\title{
Caracterização da diversidade funcional motora e autonomia de sujeito com amiotrofia muscular espinhal tipo III
}

\author{
Characterization of motor functional diversity and \\ autonomy of subject with type III spinal muscular amyotrophy
}

Ana Ivone Antonia de Oliveira ${ }^{1}$, Márcia Cristina Bauer Cunha²

${ }^{1}$ Curso em Tecnologia Assistiva para Autonomia, Participação e Inclusão Social das Pessoas com Deficiência, FMABC - Santo André (SP); e Instituto de Tecnologia Social (ITS Brasil) - São Paulo (SP), Brasil.

${ }^{2}$ Curso de Fisioterapia da FMABC - Santo André (SP); e Laboratório de Esclerose Lateral Amiotrófica, Universidade Federal de São Paulo

(UNIFESP) - São Paulo (SP), Brasil.

DOI: http://dx.doi.org/10.7322/abcshs.v38i1.9

\begin{abstract}
RESUMO
Introdução: Conforme a Organização Mundial da Saúde existem no mundo aproximadamente 610 milhões de pessoas com algum tipo de deficiência. As doenças neuromusculares (DNM) causam deficiências que levam à incapacidade física por perda de força. Entre as DNMs, a atrofia muscular espinhal (AME) é uma doença genética que afeta o corpo do neurônio motor na ponta anterior da medula espinhal. Relato de Caso: Realizado estudo descritivo com abordagem qualitativa e exploratória sobre um indivíduo com diagnóstico de AME tipo III (Doença de Kugelberg-Welander). A coleta de dados ocorreu de janeiro a março de 2012 por meio de questionário elaborado pelos autores contendo 20 questões sobre autonomia e independência individual. O sujeito relata infância típica de criança com deficiência motora, a importância da vida profissional e relacionamento social para sua satisfação pessoal. Ressalta seu esforço para ajudar outros indivíduos com diversidade funcional. Percebe-se a importância de tecnologia assistiva a sua vida. Conclusão: $O$ estudo apresenta um indivíduo cuja deficiência não impediu que lutasse para ter uma vida satisfatória dentro dos seus próprios limites.
\end{abstract}

Palavras-chave: doenças neuromusculares; pessoas com deficiência; autonomia profissional; autonomia pessoal.

\begin{abstract}
Introduction: According to the World Health Organization there are approximately 610 million people with some sort of disability in the world. Neuromuscular diseases (NMD) cause deficiencies which lead to physical disability due to loss of strength. Among NMDs, the Spinal Muscular Atrophy (SMA) is a genetic disease that affects the body from motor neurons in the anterior horn of the spinal cord. Case Report: A descriptive study with qualitative and exploratory approach was carried out about one subject with type III AME diagnostic (Kugelberg-Welander Disease). Data were collected from January through March 2012 using a 20-item questionnaire developed by the authors about autonomy and individual independency. Subject reported a typical childhood of an infant presenting motor disability and the importance of professional life and social relations for personal satisfaction. Subject emphasizes the efforts to help other individuals with functional diversity. The importance of assistive technology for subject life is noticed. Conclusion: The study presents an individual whose disability has not prevented to fight for a fulfilling life within own limitations.
\end{abstract}

Keywords: neuromuscular diseases; disabled persons; professional autonomy; personal autonomy. 


\section{INTRODUÇÃO}

Conforme estimativas da OMS (Organização Mundial da Saúde) ${ }^{1}$, existem no mundo aproximadamente 610 milhões de pessoas com algum tipo de deficiência, das quais cerca de $63 \%$ fazem parte da população economicamente ativa.

No Brasil, resultados do Censo realizado em 2000 mostram a existência de 24,5 milhões de pessoas com deficiência ${ }^{2}$. Desse total, aproximadamente $42 \%$ (ou 10,2 milhões) possuem deficiências severas, tais como deficiência mental permanente, tetraplegia, paraplegia ou hemiplegia permanente, falta de um membro ou parte dele e incapacidade ou ainda, dificuldade permanente para caminhar, subir escadas, enxergar e ouvir ${ }^{2}$. A maior proporção encontra-se no Nordeste $(16,8 \%)$ e a menor, no Sudeste $(13,1 \%)^{2}$.

Dentre as deficiências severas, é possível citar a atrofia muscular espinhal (AME). A AME é uma doença neuromuscular (DNM). As DNMs apresentam acometimentos diversos e caracterizam-se, comumente, por distúrbios isolados raros, hereditários ou adquiridos, que levam à incapacidade física por perda de força ${ }^{3}$. As AMEs são causadas primariamente pelo envolvimento da unidade motora e assiduamente determinam a perda da deambulação ${ }^{3}$.

A diminuição da funcionalidade está intensamente relacionada com as DNMs que durante sua progressão comprometem atividades simples e cotidianas, como a perda de funções básicas e a incapacidade para realização dos cuidados pessoais ${ }^{3}$.

A AME é uma DNM de herança autossômica recessiva, raramente dominante, que afeta o corpo do neurônio motor na ponta anterior da medula espinhal ${ }^{4}$, causando a diminuição da força dos músculos respiratórios que leva à morte por insuficiência respiratória ${ }^{3}$. Clinicamente, nota-se fraqueza muscular, atrofia e hipotonia difusas com predomínio nas partes proximais dos membros, associadas a fasciculações e arreflexia tendínea. Os músculos respiratórios, bulbares e paravertebrais são usualmente afetados, ao contrário dos músculos faciais e oculares ${ }^{4}$.

A $\mathrm{AME}^{5}$ é considerada como exemplo de heterogeneidade ou desigualdade alélica - ou seja, apresenta mutações do mesmo gene com fenótipos diferentes. É classificada como:

- Tipo I - Doença de Werdnig-Hoffmann (aguda fatal): 95\% das crianças afetadas vêm a óbito nos primeiros oito meses de vida ${ }^{5}$.

- Tipo II - Forma Intermediária: a expectativa de vida varia de acordo com o grau de comprometimento da musculatura respiratória. Comumente, as crianças desenvolvem escoliose ${ }^{5}$.

- Tipo III - Doença de Kugelberg Welander: caracteriza-se por sua manifestação clínica, com início entre cinco e quinze anos de idade; quanto mais tarde sua manifestação ocorrer ao início da doença, mais benigna a sua evolução. O comprometimento muscular é simétrico e de predomínio proximal. Há comprometimento da cintura escapular e, posteriormente, da cintura pélvica e membros inferiores, havendo dificuldade para subir e descer escadas. A pseudo-hipertrofia das panturrilhas pode manifestar-se em alguns pacientes, podendo também ocorrer tremor nas extremidades superiores. Há presença de hiperlordose lombar, abdômen protuso e retrações de flexores dos joelhos e do tendão de Aquiles. A doença é relativamente benigna e a maioria dos casos tem uma sobrevida normal, sendo possível a deambulação por muitos anos ${ }^{3,5}$.

- Tipo IV - Considerada benigna, acomete o indivíduo na fase adulta.

Indivíduos com AME apresentam respostas variadas ao treinamento motor, pois dependem do grau e velocidade de progressão da fraqueza e fadiga, considerando ainda o nível de condicionamento físico. A prática de atividade física e/ou exercícios terapêuticos deve ser enfrentada como uma maneira de melhorar a qualidade de vida dos pacientes ${ }^{5}$. A abordagem terapêutica nos pacientes com AME, apesar de heterogênea e complexa, mostra ao mesmo tempo semelhanças e diferenças. Pode ser diferente porque cada tipo de doença tem um agente causal específico, com forma específica de evolução e prognóstico ${ }^{5}$.

Durante séculos as pessoas com deficiência foram marginalizadas pela sociedade, isoladas em instituições ou em suas próprias casas ${ }^{6,7}$. A partir da década de 1960 iniciaram-se os movimentos reivindicatórios, organizados pelas pessoas com deficiência, que passaram a lutar por seus direitos ${ }^{2}$. As conquistas pouco a pouco foram se modificando e se transformando em leis; hoje, tanto a legislação nacional quanto a internacional incluem a garantia de acesso da pessoa com alguma deficiência ao trabalho. Atualmente tem-se verificado uma presença crescente de pessoas com deficiência nos espaços públicos. Os avanços tecnológicos têm permitido a essas pessoas maior autonomia e, consequentemente, uma participação mais ativa no mercado de trabalho e na vida social ${ }^{6,7}$. A integração social das pessoas com deficiência representa grande conquista, e isso significa o resgate da cidadania desses indivíduos ${ }^{8}$.

De modo geral, as DNM são doenças genéticas progressivas, altamente incapacitantes, e com poucas pesquisas na área de reabilitação, tornando-se indispensável aprofundar o conhecimento sobre a tecnologia assistiva $(\mathrm{TA})^{7}$, um recurso significante que pode complementar a prática fisioterapêutica e agregar mais benefícios no processo de reabilitação dos indivíduos acometidos por debilidades físicas motoras².

O objetivo deste estudo foi identificar a autonomia de um indivíduo com AME tipo III.

Foi realizado um estudo descritivo com abordagem qualitativa e exploratória. A coleta de dados do sujeito ocorreu de janeiro a março de 2012, após aprovação do projeto no Comitê de Ética em Pesquisa da Faculdade de Medicina do ABC (FMABC), sob o protocolo ${ }^{\circ}$ 082/2011. Realizou-se um levantamento por meio de um questionário elaborado pelos autores, contendo 20 questões sobre autonomia e independência de uma pessoa com deficiência física motora.

\section{RELATO DO CASO}

A. E. F., 35 anos, sexo masculino, natural de Santo André, solteiro, com diagnóstico de Amiotrofia Muscular Espinhal tipo III, conhecida também como "doença de Kugelberg-Welander". Ele 
relatou que nasceu de parto cesárea sem complicações, tem dois irmãos e mora com a mãe, o irmão e a cunhada. Possui grau de escolaridade superior concluído com formação em Advocacia. Trabalha no Poder Público atuando como Assessor de Políticas Públicas para Pessoas com Deficiência.

A. E. F. apresentou infância típica e foi acometido por DNM: "No inicio eu fiz muitas visitas a vários médicos, ortopedistas, neurologistas e outros. Fiz algumas cirurgias corretivas, alongamentos de tendões devido a encurtamentos, biópsias para detectar a deficiência. Quando eu era pequeno meus pais sempre me levaram para fisioterapia; mesmo com dificuldades de locomoção eles não me deixavam sem o tratamento fisioterapêutico, que era importante para que eu tivesse mais qualidade de vida; na época a minha mãe não dirigia, ela pegava ônibus e trem para me levar, carregando-me no colo até o local da fisioterapia. Nessa fase, fui em tudo que era benzedeira e outros tipos de terapias alternativas. Fazia natação, depois passei a fazer fisioterapia e hidroterapia apenas".

"Quando eu era criança tinha outras dificuldades de locomoção, mas conseguia me arrastar de bumbum dentro de casa; porém, os meus pais não gostavam que eu fizesse isso; sendo assim, passei a andar de motoquinha por todos os lados; depois, conforme fui crescendo me locomovia dos locais com mais facilidade, mas devido ao crescimento das pernas, aos poucos não foi possível arrastar-me pelo chão".

"Nunca andei de joelhos sozinho, para andar de gatinho só apoiando os cotovelos e andar mesmo sozinho nunca. Umas duas ou três vezes senti uma força estranha e consegui andar alguns passos sozinhos, mas foi algo muito estranho pra mim".

"Na piscina já era diferente, eu andava, nadava..., a primeira vez que entrei na piscina minha mãe até chorou porque eu estava andando... Sempre fiz fisioterapia e hidroterapia, apenas estou parado desde o ano de 2008".

Em suas respostas, destaca-se a importância atribuída a sua vida profissional: "Comecei trabalhar com 16 anos ajudando minha tia, ela tinha um comércio de vendas de relógios, eu fazia atendimento aos clientes, organizava a parte administrativa e os vendedores".

"Formei-me em 1999, em 2000 eu estudava para prestar o exame da Ordem dos Advogados quando meu pai adoeceu, ele tinha uma empresa de informática, vendas, manutenção de hardware e desenvolvimento de softwares, sendo assim acabei assumindo a empresa".

"Minha mãe sempre esteve comigo, sendo minhas pernas no ir e vir do dia a dia, mas em 2006 ela teve um derrame que a impossibilitou de realizar suas atividades diárias".

"Neste momento passei por uma transição e acabei vendendo minha empresa e fui trabalhar numa loja de tintas do meu irmão, era uma atividade mais tranquila e não necessitava de tanto deslocamento como eu tinha na minha empresa".

"Em 2008 surgiu um convite feito pelo prefeito para que eu me tornasse político e contribuísse com políticas públicas para pessoas com deficiência; aceitei o convite, vendo a oportunidade de ajudar pessoas com diferenças funcionais; foi nesse momento que assumi o cargo como Assessor lutando sempre para que pessoas com algum tipo de deficiência tivessem uma vida melhor".

$\mathrm{O}$ indivíduo afirmou que tem satisfação no trabalho. Porém, quando não respeita os seus limites, sente dores na região cervical e na cabeça.

Em relação a sua autonomia em casa, no trabalho e na sociedade, o entrevistado relata: "Minha autonomia em casa é tranquila e total, no trabalho atualmente está bem tranquilo, mas quando comecei a trabalhar encontrei muitas dificuldades arquitetônicas; na sociedade em relação às pessoas não tenho sinceramente nenhum problema referente à autonomia, mas com certeza as barreiras arquitetônicas são ainda nosso maior problema. Tenho vantagem por possuir condições financeiras mínimas pra que eu receba mais auxilio, até mesmo por ser magro fica mais fácil as pessoas me ajudarem a vencer essas barreiras".

O indivíduo relatou seu esforço para melhorar a qualidade de vida de outras pessoas com deficiência física: "Tenho trabalhado muito para isso, aliás, esse é o meu trabalho, além de atuar implantando políticas de acessibilidade e inclusão, escrevo artigos para revistas e jornais da região levando ao público mais conhecimento e contato com o assunto 'deficiência'. Tenho feito palestras em escolas e em empresas também com intuito de sempre quebrar os preconceitos e paradigmas que as pessoas têm em relação a essa temática. Sou também coordenador do Grupo de Trabalho (GT) da Pessoa com deficiência, ali discutimos tudo sobre essas políticas”.

A posição do entrevistado em relação ao preconceito é: "A gente sofre algumas vezes, mas sinceramente não me preocupo com isso, acho que devemos combater os preconceitos com informações, muitas vezes o que acontece é falta de informação do indivíduo e falta de convívio com pessoas que tenham deficiência”.

Diante de suas limitações físicas argumentou que isso nunca impediu que tivesse bom relacionamento familiar, com colegas de trabalho, chefia ou no meio social do qual fazia parte. Também quando ia para a escola sempre manteve bons relacionamentos com professores e colegas. Completou ainda dizendo: "acho que isso vai muito de como nós nos posicionamos em relação às pessoas, sempre fui muito alegre, comunicativo e isso ajudou muito".

A maior dificuldade que encontrou quando foi para a escola foram as barreiras arquitetônicas que continuam sendo desafios para pessoas com diversidade funcional.

Perguntado se é feliz e realizado, responde: "Sou feliz, agora realização é algo constante e sempre estamos à procura de novas realizações”.

Referente à Tecnologia Assistiva (TA), informou que utiliza dispositivos, como cadeira de rodas para locomoção e BIPAP (Bi Level Positive Airway Pressure) quando dorme para tratamento da apneia obstrutiva do sono.

Em relação às atividades de vida diárias, o indivíduo afirmou que realiza sozinho: banho, alimentação, vestir as roupas e suas necessidades fisiológicas. Só necessita da ajuda de terceiros para transferência da cadeira de rodas para a cama e da cama para cadeira de rodas. 


\section{DISCUSSÃO}

A. E. F. apresentou infância típica da AME tipo III. A literatura científica afirma que as DNM são genéticas, hereditárias e progressivas e que possuem em comum a falta de força muscular que afeta especialmente a unidade motora (corpo neuronal na medula, nervo periférico, placa mioneural e tecido muscular $)^{8}$. A debilidade da força muscular provoca alteração na qualidade de vida $(\mathrm{QV})^{2,8}$, levando o individuo à necessidade de apoios e/ou ajudas técnicas ou $\mathrm{TA}^{2,9}$ como: cadeiras de rodas elétricas, cadeira de rodas manual para sua locomoção, computadores para a escrita, apoios de cabeça, ajudas diversas para a manipulação, veículos de transportes adaptados, entre outros.

Conforme estudos ${ }^{5,10}$, os músculos pulmonares e o coração são afetados com frequência, provocando dificuldades respiratórias e cardíacas decorrentes da limitação da função motora de tronco e membros causada pela fraqueza muscular e gerando a deformidade postural (escoliose) ${ }^{11}$, limitação da mobilidade e da execução de atividades diárias e, neste caso, é essencial a intervenção cirúrgica de correção, que substancialmente melhora a qualidade de vida da pessoa acometida por DNM com escolioses. Apesar de o indivíduo não ter referido em seu relato, apresentava escoliose em forma de "S".

As DNM apresentam um grande impacto na QV tanto em crianças, como adolescentes e adultos. De acordo com Abresch ${ }^{12}$ et al., constituem um desafio para os profissionais envolvidos no processo de reabilitação desses indivíduos.

Após manifestados os primeiros sintomas, as DNM vão evoluindo sempre, às vezes mais rápido, outras vezes mais devagar; contudo, no decorrer do tempo, os doentes apresentam problemas graves de falta de força e perda de autonomia ${ }^{12}$, levando-os a necessitar da ajuda de terceiros para realizar as atividades de vida diária simples como: ir ao banheiro, tomar banho, levantar-se da cama, vestir-se, escovar os dentes, acender as luzes, necessitando também da utilização de dispositivos como bengala, cuidados de apoio e uso de tecnologia, visando melhor qualidade de vida ${ }^{2,12,13}$.

Conforme o estudo de Boyer et al. ${ }^{14}$, todos os pacientes com DNM desejam permanecer independentes, ou seja, com autonomia, querem ser capazes de manter o controle sobre suas vidas. Eles evitam a todo o custo tornar-se dependentes de terceiros, seja em casa, no local de trabalho ou durante as atividades de lazer. No caso do A. E. F. ficou evidente que a vida profissional foi fundamental para sua satisfação pessoal.

As pessoas com diferença funcional deveriam locomover-se livremente em todos os segmentos sociais com autonomia ${ }^{6}$. No entanto, ainda há barreiras visíveis e o preconceito persiste. O reconhecimento e respeito pela diversidade funcional deveriam estar presentes nas áreas da saúde, educação, mercado de trabalho, turismo, lazer, transporte e equipamentos públicos ${ }^{4}$; ainda há muito a ser feito para que estes se tornem regra geral e não exceção à cidadania ${ }^{6,7}$.

Conforme estudos, as pessoas com deficiência são cidadãos e fazem parte da sociedade, e esta deve preparar-se para lidar com a diversidade humana ${ }^{2}$. Na atualidade é primordial ter consciência de que todos os indivíduos devem ser respeitados e aceitos, não importa o sexo, a idade, as origens étnicas, opção sexual ou suas deficiências². A limitação de uma pessoa não diminui seus direitos, portanto, a sociedade deve estar aberta a todos, estimulando a participação de cada um, reconhecendo as diferentes experiências humanas e apreciando o potencial de todos ${ }^{2}$.

Algumas pesquisas estão construindo um futuro livre de termos como deficiências ${ }^{15}$. A diversidade funcional tem mudado sua aparência nestas últimas décadas com a sofisticação dos recursos e materiais disponíveis para corrigir, minimizar e até eliminar as várias diferenças funcionais. A TA identifica todo arsenal de recursos e serviços que cooperam para ampliar as habilidades funcionais de pessoas com deficiência, necessárias para promover a manutenção ou aumento das habilidades funcionais; contribui para melhora do aprendizado, do trabalho, da interação com a família e os amigos, sendo, no entanto, essencial na promoção de QV dos pacientes com $\mathrm{DNM}^{7}$. Essas inovações são bem recebidas por diversos motivos, entre eles a melhoria da qualidade de vida, até a eliminação de um antigo desconforto experimentado em face da diversidade funcional de muitas pessoas ${ }^{2,12,13}$.

Conforme a análise em três estudos: Pontes ${ }^{1}$, Carbonero ${ }^{8}$ e Vuillerot $^{15}$, a Distrofia Muscular de Duchenne é a doença neuromuscular mais frequente, seguida pela Atrofia Muscular Espinhal e outras. De acordo com Baioni ${ }^{11}$, A atrofia muscular espinhal é a principal desordem fatal com esse caráter genético depois da fibrose cística (1:6.000), com uma incidência de 1:6.000 a 1:10.000 nascimentos. A AME ainda não tem cura, porém, alguns cuidados básicos referentes à nutrição, respiração e fisioterapia podem ser importantes para retardar o progresso da doença e prolongar a vida desses pacientes ${ }^{1,8}$.

De acordo com Vuillerot ${ }^{15}$ em relação à pontuação do escore sobre QV aplicado em adolescentes com DNM, foram considerados inesperadamente altos: o bem-estar físico e psicológico, vitalidade, imagem corporal; e as relações com os pais e amigos e com a escola foram significativamente mais satisfatórias do que entre os colegas sem deficiência. Esses indivíduos parecem compensar sua debilidade motora por um maior envolvimento na escola ${ }^{15}$. Nessa amostra e na maioria das dimensões, os adolescentes com DNM expressaram satisfação com a vida igual ou melhor do que os colegas sem deficiência ${ }^{15}$.

Entende-se que para uma pessoa com algum tipo de deficiência conseguir obter um equilíbrio emocional positivo é indispensável um processo constante de adaptação da capacidade de resolver problemas, atendendo às questões determinadas pela vida cotidiana, fato que pode contribuir para a construção de sua autoimagem positiva. Existem fatores que influenciam fortemente para o processo de integração social da pessoa com deficiência. São aqueles que dependem inteiramente das melhorias nas condições estruturais como a acessibilidade, o aumento de meios de transportes adaptados, o atendimento integral às necessidades individuais e outros.

Sabe-se que algumas das estratégias utilizadas por pessoas com AME para ter uma vida melhor são: o estabelecimento forte de 
relacionamento com a família, amigos e colegas de trabalho; dentro da sociedade procuram ter uma vida normal com independência e possibilidades de estudar e trabalhar, buscam ser membros produtivos, como é o caso de A. E. F., que se mobilizou para ajudar outras pessoas com diversidade funcional.

A utilização da entrevista enquanto instrumento qualitativo não padronizado facilitou a observação da subjetividade do participante deste estudo, fato esse que favoreceu uma maior aproximação com a realidade do seu dia a dia, e não abordando apenas uma vida de qualidade.
Conclui-se que, embora este estudo tenha envolvido apenas um indivíduo com AME, consideramos importante o seu relato, pois demonstrou que sua deficiência não impediu que lutasse para ter uma vida normal dentro dos seus limites. Isso ilustra o paradoxo da deficiência. Existem pessoas com deficiência que procuram adaptar-se a uma nova condição de vida, dando-lhe sentido com realizações que lhes promovam satisfações e bem-estar no seu cotidiano. A percepção deste cidadão foi valiosa, já que ele vivencia dificuldades existentes no Brasil e vem enfrentando as barreiras sociais, físicas e atitudinais dia após dia.

\section{REFERÊNCIAS}

1. World Health Organization. World report on disability. 2011; p. 8-11.

2. Federação Brasileira de Bancos (FEBRABAN). População com deficiência no Brasil fatos e percepções. 2006; p.10-45.

3. Pontes JF, Ferreira GMH, Sena-Evangelista KCM, Dourado Junior ME, Fregonezi G. Força muscular respiratória, perfil postural e nutricional em crianças com doenças neuromusculares. Fisioter Mov. 2012;25(2):253-61.

4. Orsini M, Freitas MRG, Sá MRC, Mello MP, Botelho JP, Antonioli RS, et al. Uma revisão das principais abordagens fisioterapêuticas nas atrofias musculares espinhais. Rev Neurocienc. 2008;16(1):46-52.

5. Cunha MCB. Efeitos da oxandrolona (esteroide anabólico androgênico) e dos exercícios aquáticos no tratamento de pacientes com doenças neuromusculares. Tese [Doutorado] Universidade Federal de São Paulo - Escola Paulista de Medicina. São Paulo: 2004; p. 6-7.

6. Galvão Filho TA; Damasceno LL. Tecnologia assistiva em ambiente computacional: recursos para a autonomia e inclusão socio-digital da pessoa com deficiência. Programa InfoEsp: Premio Reina Sofia 2007 de Rehabilitación y de Integración. In: Boletín del Real Patronato Sobre Discapacidad, Ministerio de Educación, Política Social y Deporte. Madri (Espanha): 2008;(63):14-23.

7. Pereira R. Diversidade funcional: a diferença e o histórico modelo de homem-padrão. História, Ciências, Saúde - Rio de Janeiro: Manguinhos; 2009; 16(3):715-28.
8. Carbonero FC, Zago GM, Campos D. Tecnologia Assistiva na Distrofia Muscular de Duchenne: aplicabilidade e benefícios. Rev Neurocienc. 2012;20(1):109-16.

9. Darabas KC, Comim CM, Tuon L. Análise da funcionalidade e qualidade de vida em pacientes portadores de doenças neuromusculares. Fisioter Brasil. 2009;10(4):241-7.

10. Strehle EM. Long-term management of children with neuromuscular disorders. J Pediatr (Rio J). 2009;85(5):379-84.

11. Baioni MTC, Ambiel CR. Spinal muscular atrophy: diagnosis, treatment and future prospects. J Pediatr (Rio J). 2010;86(4):261-70.

12. Abresch RT, Seyden NK, Wineinger MA. Quality of life: Issues for persons with neuromuscular diseases. Phys Med Rehabil Clin N Am. 1998;9(1):233-48.

13. Huismann DJ, Sheldon JP, Yashar BM, Amburgey K, Dowling JJ, Petty EM. Quality of life and autonomy in emerging adults with early-onset neuromuscular disorders. J Genet Couns. 2012;21(5):713-25

14. Boyer F, Morrone I, Laffont I, Dizien O, Etienne JC, Novella JL. Health related quality of life in people with hereditary neuromuscular diseases: an investigation of test-retest agreement with comparison between two generic questionnaires, the Nottingham health profile and the short form-36 items. Neuromuscular Disord. 2006;16(2):99-106.

15. Vuillerot C, Hodgkinson I, Bissery A, Schott-Pethelaz AM, Iwaz J, Ecochard R, et al. Self-perception of quality of life by adolescents with neuromuscular diseases. J Adolesc Health. 2010;46(1):70-6. 